\title{
Effects of short-term ingestion of Russian Tarragon prior to creatine monohydrate supplementation on whole body and muscle creatine retention: a preliminary investigation
}

\author{
Jonathan M Oliver ${ }^{1}$, AR Jagim', A Sanchez', K Kelley', Elfego Galvan', James Fluckey', S Riechman', \\ Mike Greenwood', Ralf Jäger ${ }^{2}$, M Purpura ${ }^{2}$, I Pischel ${ }^{3}$, Richard B Kreider ${ }^{1^{*}}$
}

From International Society of Sports Nutrition: 9th Annual ISSN Conference and Expo

Clearwater, FL, USA. 22-23 June 2012

\section{Background}

It has been well-established that creatine monohydrate (CrM) increases whole body creatine retention and muscle creatine content. Extracts of Russian Tarragon (RT) have been reported to produce anti-hyperglycemic effects [1] and influence plasma creatine levels during the ingestion of CrM [2]. Theoretically, RT ingestion with CrM may promote greater creatine retention than ingesting $\mathrm{CrM}$ alone. The purpose of this preliminary study was to determine if short-term, low-dose aqueous RT extract ingestion prior to CrM supplementation influences whole body creatine retention or muscle creatine content.

\section{Methods}

In a double-blind, randomized, and crossover manner; 10 untrained males $(20 \pm 2 \mathrm{yrs} ; 179 \pm 9 \mathrm{~cm} ; 91.3 \pm 34 \mathrm{~kg})$ ingested $500 \mathrm{mg}$ of aqueous Tarragon extract (Finzelberg, Andernach, Germany) or $500 \mathrm{mg}$ of a placebo (P) 30 -minutes prior to ingesting $5 \mathrm{~g}$ of CrM (Creapure ${ }^{\mathbb{B}}$, AlzChem AG, Germany) (CrM+RT). Subjects ingested the supplements two times per day (morning and evening) for 5 -days and then repeated the experiment after a 6-week wash-out period. Urine was collected at baseline and during each of the 5-days of supplementation to determine urine creatine content. Whole body creatine retention was estimated as the difference from orally ingested $\mathrm{CrM}(10 \mathrm{~g} / \mathrm{d})$ from the amount of creatine excreted daily in urine. Muscle biopsies were also

\footnotetext{
* Correspondence: rkreider@hlkn.tamu.edu

'Department of Health and Kinesiology, Exercise and Sport Nutrition

Laboratory, Texas A\&M University, College Station, TX 77843, USA

Full list of author information is available at the end of the article
}

obtained from the vastus lateralis at baseline and after 3 and 5 days of supplementation for determination of muscle free creatine content. Data were analysed by MANOVA with repeated measures.

\section{Results}

Daily urinary excretion of creatine increased in both groups from baseline $(0.4 \pm 0.5 ; 1.9 \pm 1.4,3.5 \pm 2.4,4.4 \pm 3.2$, $3.9 \pm 2.6,5.2 \pm 3.1 \mathrm{~g} / \mathrm{d} ; \mathrm{p}=0.001)$ with no differences observed between groups $(\mathrm{CrM}+\mathrm{P} 0.34 \pm 0.4,1.9 \pm 1.6,3.5$ $\pm 2.3,4.7 \pm 3.3,3.2 \pm 2.8,5.0 \pm 3.4 ; \mathrm{CrM}+\mathrm{RT} 0.5 \pm 0.6,1.7$ $\pm 1.1,3.4 \pm 2.7,4.2 \pm 3.3,4.6 \pm 2.2,5.4 \pm 3 / 2 \mathrm{~g} / \mathrm{d} ; \mathrm{p}=0.59$ ). Whole body daily creatine retention increased following supplementation $(0.0 \pm 0.0 ; 8.2 \pm 1.4,6.5 \pm 2.4,5.6 \pm 3.2,6.1$ $\pm 2.6,4.8 \pm 3.2 \mathrm{~g} / \mathrm{d} ; \mathrm{p}=0.001$ ) with no differences observed between groups $(\mathrm{CrM}+\mathrm{P} 0.0 \pm 0.0,8.1 \pm 1.6,6.5 \pm 2.4,5.3$ $\pm 3.2,6.8 \pm 2.8,5.0 \pm 3.4$; $\mathrm{CrM}+\mathrm{RT} 0.0 \pm 0.0,8.3 \pm 1.1,6.6$ $\pm 2.7,5.8 \pm 3.3,5.4 \pm 2.2,4.6 \pm 3.2 \mathrm{~g} / \mathrm{d} ; \mathrm{p}=0.59$ ). Total whole body creatine retention during the supplementation period were not significantly different among groups expressed in total grams retained $(\mathrm{CrM}+\mathrm{P} 31.7 \pm 11.1$; $\mathrm{CrM}+\mathrm{RT} 30.6 \pm 10.3 \mathrm{~g} ; \mathrm{p}=0.82)$ or percentage retained (CrM+P 63.4 $\pm 22.3 \%$; CrM+RT 61.2 $\pm 19.9 \%$; $\mathrm{p}=0.82$ ) over the supplementation period. There was significant variability in muscle phosphagen levels, therefore, only muscle free creatine data are reported. After 3 and 5-days of supplementation, respectively, both supplementation protocols demonstrated a significant increase in muscle free creatine content from baseline $(4.8 \pm 16.7,15.5 \pm 23.6$ $\mathrm{mmol} / \mathrm{kg} \mathrm{DW}, \mathrm{p}=0.01$ ) with no significant differences observed between groups ( $\mathrm{CrM}+\mathrm{P} 9.3 \pm 14.3,22.8 \pm 28.2$; $\mathrm{CrM}+\mathrm{RT} \quad 0.3 \pm 18.4,8.1 \pm 16.2 \mathrm{mmol} / \mathrm{kg} \mathrm{DW}$; $=0.34$ ). 
In percentage terms, muscle free creatine content in both groups increased over time $(\mathrm{p}=0.008)$ by $10.9 \pm 27 \%$ and $23.5 \pm 34 \%$ after 3 and 5 -days, respectively, with no differences observed between groups $(\mathrm{CrM}+\mathrm{P} 0.0 \pm 0.0$, $21.1 \pm 30,37.3 \pm 42$; CrM+RT $0.0 \pm 0.0,0.7 \pm 21,9.6 \pm 18 \%$, $\mathrm{p}=0.13)$.

\section{Conclusions}

Results indicate that ingesting as little as $5 \mathrm{~g}$ of CrM taken twice daily increases total muscle creatine content by 23.5 $\pm 34.5 \%$. However, our preliminary findings indicate that ingesting RT 30-min prior to CrM supplementation did not affect whole body creatine retention or muscle free creatine content during a short-period of creatine supplementation (10 g/d for 5-days) in comparison to ingesting a placebo prior to CrM supplementation. Additional research is needed with a larger sample size to examine: 1.) whether ingestion of greater amounts of RT prior to and/or in conjunction with CrM ingestion would affect creatine retention; 2.) whether ingestion of RT with CrM over longer periods of time would affect creatine retention; and, 3.) whether co-ingesting RT with CrM and carbohydrate may reduce the need for ingesting carbohydrate with $\mathrm{CrM}$ in order to promote greater creatine retention.

\section{Acknowledgements}

Supported by the Martin Bauer Group, Finzelberg GmbH \& Co. KG.

\section{Author details}

'Department of Health and Kinesiology, Exercise and Sport Nutrition Laboratory, Texas A\&M University, College Station, TX 77843, USA. ${ }^{2}$ Increnovo LLC, 2138 E Lafayette PI, Milwaukee, WI, 53202, USA. ${ }^{3}$ PhytoLab GmbH \& Co. KG, Dutendorfer Straße 5-7, 91487 Vestenbergsgreuth, Germany.

Published: 19 November 2012

\section{References}

1. Pischel I, Burkard N, Kauschka M, Butterweck V, Bloomer RJ: Potential application of Russian Tarragon (Artemisia dracunculus L.) in health and sports. J Int Soc Sports Nutr 2011, 8(Suppl 1):P16.

2. Jäger R, Kendrick IP, Purpura M, Harris RC, Ribnicky DM, Pischel I: The effect of Russian Tarragon (artemisia dracunculus L.) on the plasma creatine concentration with creatine monohydrate administration. J Int Soc Sports Nutr 2008, 5(Suppl 1):P4.

doi:10.1186/1550-2783-9-S1-P24

Cite this article as: Oliver et al:: Effects of short-term ingestion of Russian Tarragon prior to creatine monohydrate supplementation on whole body and muscle creatine retention: a preliminary investigation. Journal of the International Society of Sports Nutrition 2012 9(Suppl 1):P24.

\section{Submit your next manuscript to BioMed Central} and take full advantage of:

- Convenient online submission

- Thorough peer review

- No space constraints or color figure charges

- Immediate publication on acceptance

- Inclusion in PubMed, CAS, Scopus and Google Scholar

- Research which is freely available for redistribution

Submit your manuscript at www.biomedcentral.com/submit
C Biomed Central 